Article

\title{
Diabetic Retinopathy: An Overview on Mechanisms, Pathophysiology and Pharmacotherapy
}

\author{
Prawej Ansari ${ }^{1,2, *(\mathbb{D}}$, Noushin Tabasumma ${ }^{1} \mathbb{D}$, Nayla Nuren Snigdha ${ }^{1}$, Nawfal Hasan Siam ${ }^{1}$, \\ Rachana V. N. R. S. Panduru ${ }^{3}$, Shofiul Azam ${ }^{4}$, J. M. A. Hannan ${ }^{1}$ and Yasser H. A. Abdel-Wahab ${ }^{2}$ (D)
}

1 Department of Pharmacy, Independent University, Bangladesh (IUB), Dhaka 1229, Bangladesh; noushintabasumma@gmail.com (N.T.); nayla.nuren18@gmail.com (N.N.S.); nowfalhasan1542019@gmail.com (N.H.S.); jmahannan@iub.edu.bd (J.M.A.H.)

2 School of Biomedical Sciences, Ulster University, Co. Londonderry, Northern Ireland, Coleraine BT52 1SA, UK; y.abdel-wahab@ulster.ac.uk

3 School of Chemistry and Molecular Biosciences, University of Queensland, St Lucia, Brisbane, QLD 4072, Australia; v.panduru@uqconnect.edu.au

4 Department of Applied Life Science \& Integrated Bioscience, Graduate School, Konkuk University, Chungju 27478, Korea; azamsunnybd@kku.ac.kr

* Correspondence: pr.ansari@iub.edu.bd; Tel.: +880-13-23879720

check for

updates

Citation: Ansari, P.; Tabasumma, N.; Snigdha, N.N.; Siam, N.H.; Panduru, R.V.N.R.S.; Azam, S.; Hannan, J.M.A.; Abdel-Wahab, Y.H.A. Diabetic Retinopathy: An Overview on Mechanisms, Pathophysiology and Pharmacotherapy. Diabetology 2022, 3, 159-175. https://doi.org/10.3390/ diabetology3010011

Academic Editor: Giancarlo Tonolo

Received: 27 December 2021

Accepted: 5 February 2022

Published: 15 February 2022

Publisher's Note: MDPI stays neutral with regard to jurisdictional claims in published maps and institutional affiliations.

Copyright: () 2022 by the authors Licensee MDPI, Basel, Switzerland. This article is an open access article distributed under the terms and conditions of the Creative Commons Attribution (CC BY) license (https:// creativecommons.org/licenses/by/ $4.0 /)$.

\begin{abstract}
Diabetes mellitus is one of the most frequently occurring metabolic disorders (DMs), impairing healthy life around the globe, with mild-to-severe secondary complications. DM is associated with secondary complications, including diabetic retinopathy (DR), which damages the retina and can lead to vision loss. Diabetic patients often suffer from extreme retinal capillary aneurysms, hemorrhage, and edema, which is likely to lead to non-proliferative or proliferative diabetic retinopathy (NPDR or PDR) and diabetic macular edema (DME). Several epidemiological studies have illustrated that the occurrence of DR can vary by age of diabetes onset, diabetes type, and ethnicity. Although DR is very well-known, the complexity of its etiology and diagnosis makes therapeutic intervention difficult and challenging. We have reviewed different pathological aspects of diabetic retinopathy and its underlying mechanism of occurrence. In this review, we aim to provide an in-depth understanding and illustration of the progression of diabetic retinopathy, its pathophysiology, epidemiology, and prospective therapeutic targets.
\end{abstract}

Keywords: type 2 diabetes mellitus; hyperglycemia; insulin; retinopathy; vision loss

\section{Introduction}

Diabetic retinopathy (DR) involves microaneurysms or worse lesions affecting at least a single eye [1]. It is one of the most pervasive secondary microvascular complication intrinsic in diabetes mellitus (DM), induced by leakage from breakdown of the inner blood-retinal barrier and microvascular occlusion [2-4]. DR plays a vital role in blindness and vision impairment in the working-class population (aged 20-65 years) worldwide [5-7]. A total of $2.6 \%$ of global blindness is a resultant of hyperglycemia [2]. In South Asian developing countries, DR is infrequent (19.9\%) compared to the developed European territories (45.7\%). Within South Asia, depending on dietary patterns and lifestyle variations, the urban population is more susceptible to DR than the suburban or rural communities [8]. On the other hand, several epidemiologic studies suggest that DR is more prevalent in young individuals with type 1 rather than type $2 \mathrm{DM}$ and therefore presents a substantial burden to the socio-economy due its effects on working-aged individuals [2].

DR is nearly asymptomatic; very few visual or ophthalmic symptoms are noticed before complete blindness [6]. Its pathogenesis is also not certain [9], although some studies have demonstrated a significant co-relation with sleep apnea, post-translational amendments of histones within chromatins, and methylation of DNA and non-coding 
RNAs [6]. Some specified risk factors for DR include hyperglycemia, hypertension, obesity, age, sex, race, and genetics [9]. Hence, following a healthy diet as well as maintaining blood pressure and glucose within the normal range is likely to delay the nascence and progression of the disease [4]. DR is a progressive health challenge, but prevention is possible [3], and improved knowledge about the basic mechanisms of the disease and its early detection could minimize vision loss. This review aims to summarize the epidemiology, risk factors, management, and pharmacological intervention of diabetic retinopathy.

\section{Materials and Methods}

Data for this article were collected from PubMed and Google Scholar using the keywords 'Diabetic Retinopathy', 'Hyperglycemia and retinopathy', 'Prevalence of retinopathy', 'Risk factors of retinopathy', 'Diabetic macular edema', 'Microvascular complications', and 'Proliferative Diabetic Retinopathy'. The literature search was not limited to a small timescale but $20 \%$ of the accumulated data were published before 2000 and the remaining $80 \%$ were limited to the timescale of 20 years. We started collecting the data from July until December 2021. Around 400 papers were read to find the appropriate information, and after primary screening, 100 papers were selected and critically scrutinized. They were then summarized for the current review.

\section{Mechanism of Diabetic Retinopathy and Classification}

DR has been classified as the most commonly occurring major secondary complication in individuals diagnosed with DM [10]. It has also been classified as the most documented microvascular threat to diabetic patients [11]. A lack of diagnosis or timely therapeutic intervention could result in visual impairment, partial blindness, and ophthalmic complications beyond these effects [5]. Thus, understanding the mechanisms involved in $\mathrm{DR}$ is of great importance in order to ensure the proper diagnosis, assessment, and treatment of this disease. Depending on the pathophysiology of microvascular aneurysms, pre-retinal vascularization, retinal hemorrhages, intraretinal microvascular abnormalities (IRMA) (Figure 1), and other clinical patterns, DR can be differentiated into two major classes, namely, PDR and NPDR [12,13]. PDR primarily begins with the abnormal growth of fibrous connective tissue on the retinal surface, whereas NPDR occurs due to lesions inside the retinal capillaries resulting from edema, hemorrhage, microaneurysms of the blood vessels, and/or capillary blockage. (Figure 1) [5,12]. In addition, persistent DME as well as vascular leakage causes the formation of hard exudates at the core of the macula (Figure 1) [14]. These patterns can range from mild to severe, depending upon the onset and duration of the complications. Multiple types of research have been conducted and are ongoing, yet the pathological mechanism of DR remains unclear as a result of the absence of retinal samples of animals and the unavailability of human samples [15]. In DR formation pattern of different mediators including cytokines, growth factors, coagulation factors, neurotrophic factors, vasoactive agents, and inflammatory mediators are affected due to metabolite disturbances [15] thus can be used as therapeutic targets.

\subsection{Hyperglycaemia in Diabetic Retinopathy}

Hyperglycemia is a clinical manifestation in diabetes and refers to an escalated level of blood glucose due to an insufficiency of insulin. An escalated glucose level causes non-enzymatic glycosylation that causes an increase of complex cross-linked substances known as advanced glycation end products (AGE). AGE formation leads to numerous secondary complications, for example, the augmentation of intracellular reactive oxygen species (ROS) [15], which causes oxidative-stress-induced damage to retinal cells. In addition, the escalating production of AGE have shown reduction in standard mRNA levels of pigment epithelium-derived factor (PEDF), which coherently initiates inflammation and damage inside the microvascular endothelial cells of the retina since PEDF has a protective role $[16,17]$. This simultaneously triggers the enzyme complex nicotinamide adenine dinucleotide phosphate (NADPH) oxidase and nuclear factor-B (NF- $\mathrm{kB}$ ), leading to 
inflammation and cells damage $[15,18,19]$. The inflammation caused in the vessels includes the activities of biomolecules such as lipoprotein-PLA2, secretory phospholipase A2 IIA, and pro-inflammatory cytokines (TNF- $\alpha$ and IL-1 $\beta$ ) [20]. Similarly, the elevation in glucose levels activates the metabolic polyol pathway, which in hyperglycemic conditions causes the production of sorbitol from glucose with the cofactor NADPH. Sorbitol is consequently metabolized to fructose by sorbitol dehydrogenase using the cofactor NAD+ [21] and the reaction is regulated by an enzyme called aldose reductase (AR) [22]. Due to its hydrophilic characteristics, hyperproduction of sorbitol does damage to retinal cells by causing an intracellular osmotic imbalance [23]. Furthermore, the metabolism of fructose produces its glycosylating derivatives 3-deoxyglucosone and fructose-3-phosphate, which subsequently escalates oxidative stress at the pericytes and other retinal cells via the promotion of AGE [21,24,25].

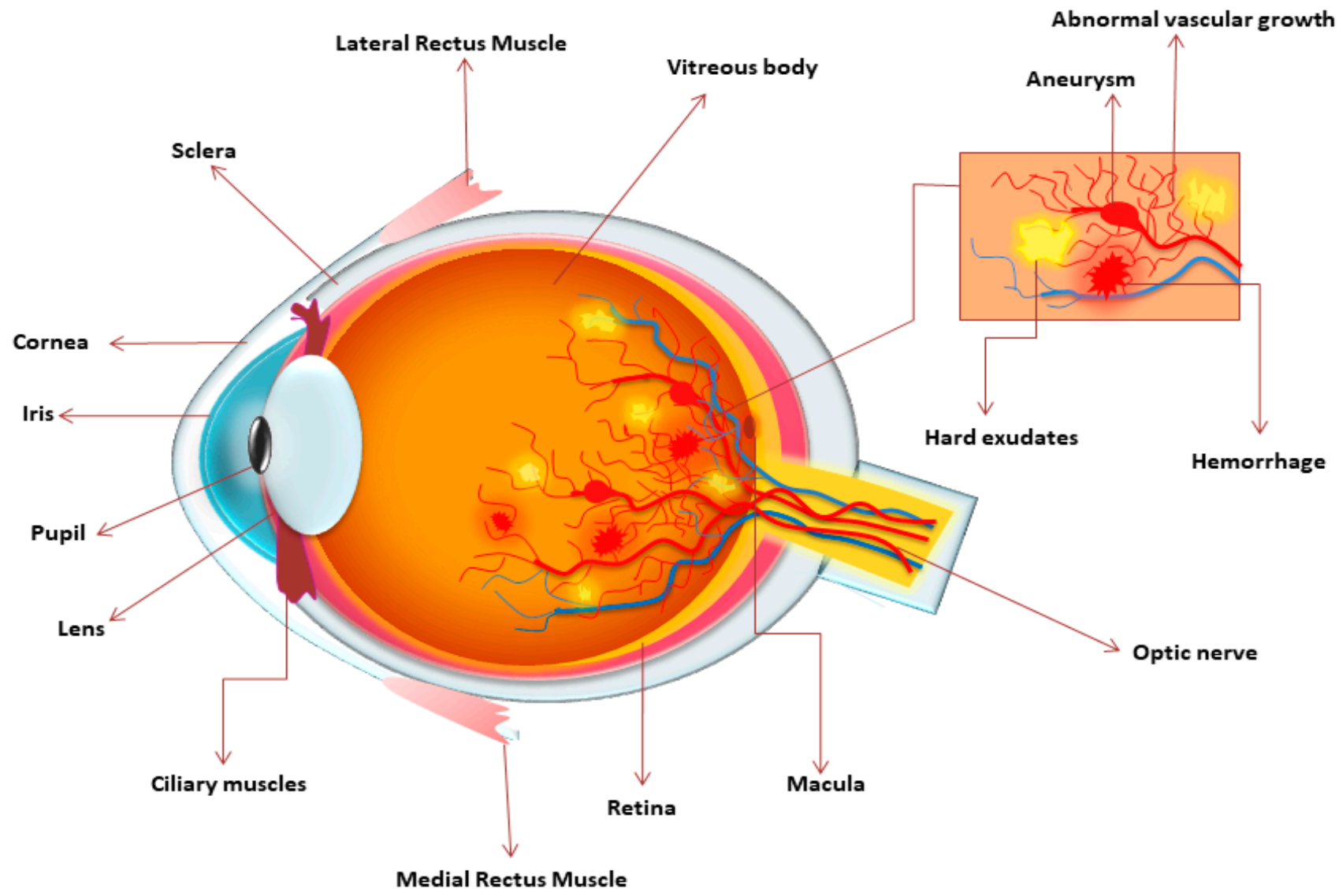

Figure 1. Different pathological complications in diabetic retinopathy: Anatomy of complications faced such as retinal vessel hemorrhage and microaneurysms, abnormal vascular development on the retinal surface, and the accumulation of yellowish thick fluids towards the middle of the retina results in edema formation.

It is evident from the prior literature that the induction of oxidative stress, compromising the retinal cells, is a direct pathway for hyperglycemia to develop into DR [15]. This increasing oxidative stress causes the loss of neuronal and pericyte cells, resulting in blocked capillaries. The blocked capillaries and increased number of blood vessels cause distortion and deformation of the microvascular structure of the retina. The degeneration of pericyte cells starts with the progressive stimulation of PKC- $\delta$ signaling, caused by elevated blood glucose levels. The signaling surge stimulates the expression of protein kinase C- $\delta$ (PKC- $\delta$, encoded by Prkcd) and p38 mitogen-activated protein kinase, and causes dephosphorylation of PDGF receptors and declines its downstream signaling and thus results in the self-mediated death of the cells of the pericytes [20]. In hyperglycemic 
situations, the elevated glucose levels cause a flux in the glycolytic pathway, which subsequently escalates intracellular NADH levels, giving simultaneous rise in the tricarboxylic acid cycle, and the ratios of lactate to pyruvate in the tissue. This reaction progresses into an influx of excessive electrons into the mitochondria that influence the formation of reactive oxygen species, again leading to retinal oxidative stress $[15,26]$. This causes DNA metabolism that potentiates the nuclear enzyme PARP (poly-adenosine diphosphate-ribose polymerase) and the accentuation of NF- $\mathrm{kB}$ activation, which enhances the formation of tumor necrosis factor- $\alpha$ (TNF- $\alpha$ ) and NF- $\mathrm{kB}$-dependent genes, producing an exacerbation in oxidative stress $[15,27]$. Controlled research conducted on galactosemic dog models, illustrated significant dot and blot hemorrhages and retinal vascular aneurysms following the manifestation of retinopathy [28]. However, the reverse action of extreme damage usually caused to the microvascular retinal cells cannot be easily done, even with highly intensive treatment and efficient glycemic control [15,29].

\subsection{Malfunction of Insulin Signaling in Retinopathy}

The peptide anabolic hormone, insulin has a major influence on the absorption of different macromolecules, such as fatty acids, carbohydrates, proteins, etc., in the cells. Insulin inversely interacts with glucagon to regulate glucose metabolism in the liver. These reactions are mediated by the signal transduction pathway [30]. The blood-retina barrier acts naturally providing immune privilege to the eye; thus, at the physiological standard level of insulin the transport mechanism across this barrier works potently [30,31]. However, with abnormal coagulation or a lack of insulin, this mechanism is disrupted. The results of research conducted on exsanguinated animals to examine insulin transport levels suggested a decline in the transport rate of insulin as the physiological function of glial, neuronal, and vascular cells of the retina were disrupted [30,32]. However, the exact pathway in which the mechanism of transport is compromised has not entirely been elucidated but some plausible causes have been proposed. Recent investigations have found that activation of the insulin receptor in retinal microvascular cells has various effects such as overlapping of insulin receptor, insulin receptor substrate-1 (IRS-1), phosphatidylinositol 3-kinase (PI3K), and phosphotyrosine in neuronal cells of rats $[30,33,34]$. Since the insulin signaling pathway is regulated by various proteins, different IR subsets are likely to signal differently than the above-mentioned routes [30]. Another study, conducted on hyperglycemic rats showed an increase in insulin receptor levels in the cells of the retina [35]. Thus, it is evident that there is a correlation of insulin level with retinopathy; however, further research needs to be conducted to elucidate the mechanism.

\section{Pathophysiology}

Diabetic retinopathy is a microvascular disease, characterized in various ways based on elevated vascular flow and vascular leakage due to the presence of vascular lesions, cell inflammation, edema in tissues, adhesion molecule expression and cytokines, reactive glia, apoptosis of inner retinal cell, and neovascularization [36]. In the pathogenesis of $\mathrm{DR}$, hyperglycemia plays an important role. The biochemical pathways associated with hyperglycemia-induced vascular damage include elevated glucose flux by means of the polyol pathway, AGE-product accumulation, inflammation, as well as the activation of protein kinase C (hexosamine pathway) [10,37]. The overabundance of superoxide in the mitochondria induced by hyperglycemia leads to oxidative stress, which acts as a stressor, linking all these metabolic pathways. Oxidative stress gives rise to multiple early clinical hallmarks of DR that include a thickened basement membrane, pericyte apoptosis, and mitochondrial dysfunction, which altogether result in BRB breakdown [37]. BRB impairment thickens the retina, as well as increasing leukocytosis, which is an intravascular immune response and one of the early clinically recognizable pathologies of DR. It causes the adherence of white blood cells (WBCs) to the endothelial cells lining the blood vessels that influence the plugging of capillaries and vascular leakage [36]. The summary of the pathophysiology is shown below (Figure 2). 


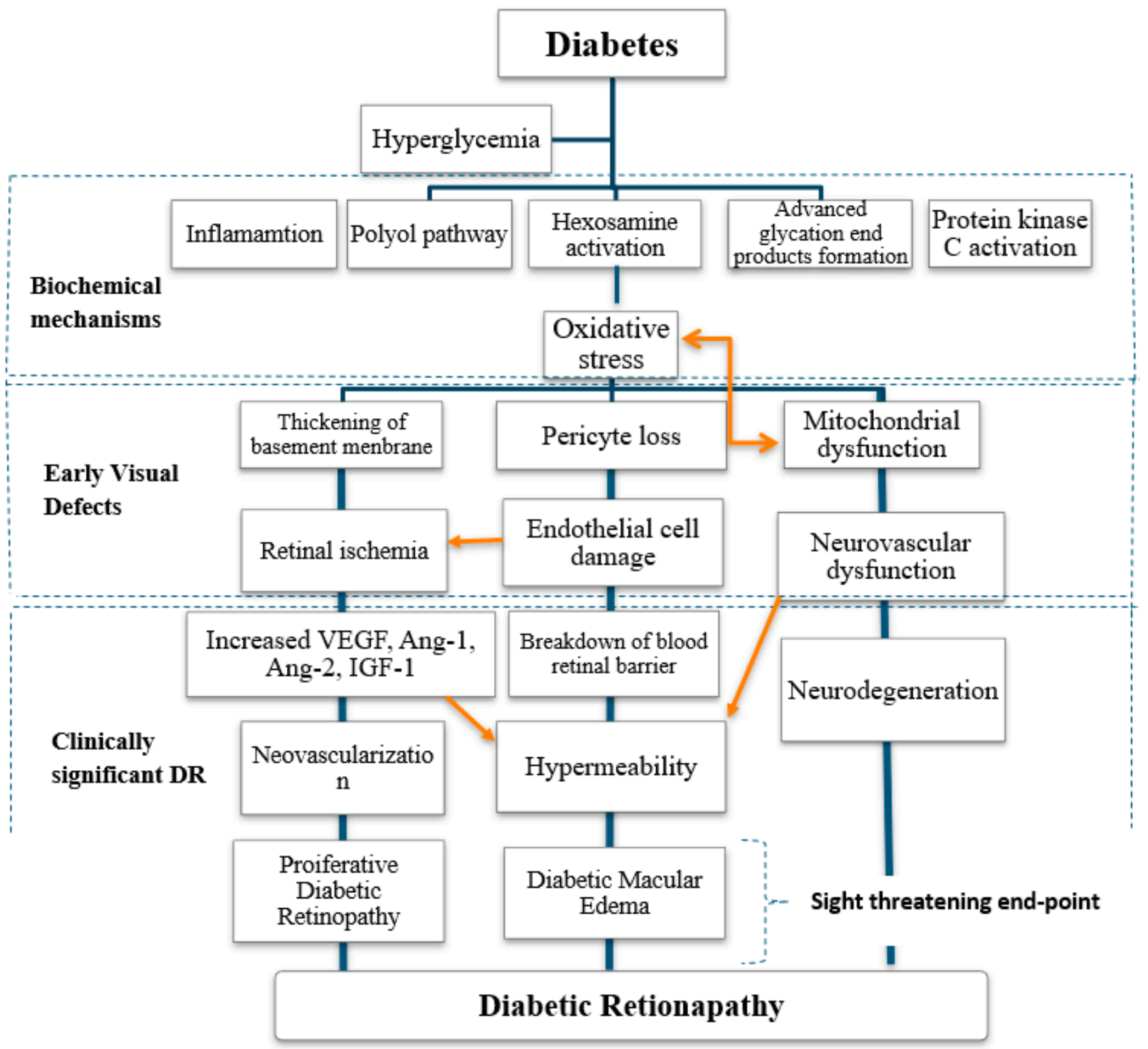

Figure 2. Diagrammatic synopsis of the pathogenesis and pathophysiology of DR.

DR arises from hyperglycemia-induced oxidative stress through a series of biochemical mechanisms. As per the microvascular pathology, endothelium damage due to pericyte loss causes hypoperfusion that leads to neovascularization and compromises the integrity of the BRB. These eventually lead to sight-threatening points, which are the major complications of DR. On the other hand, pericytes provide structural support to the capillaries; therefore, the loss of pericytes is also associated with endothelial cell damage, along with cotton wool patches, microaneurysms, and dot and blot hemorrhages. In addition, pericyte loss and damage to the endothelium leads to occlusion of capillaries and local ischemia, which activates hypoxia-inducible factor 1 (HIF-1). Subsequently, activation of this factor further increases the expression of the vascular endothelial growth factor (VEGF). Along with the other angiogenic factors Ang-1 and Ang-2, VEGF induces vascular permeability [38]. At the end stage of pathology, neovascularization and neurodegeneration play a crucial role [37]. Neurodegeneration is a result of hyperglycemia-induced downregulation of several vital neurotrophic factors, including NGF (nerve growth factor), PEDF (pigment epithelium-derived factor), IRBP (interphotoreceptor retinoid-binding protein) and somatostatin, whereas neovascularization involves the upregulation of the pro-angiogenic factors 
(VEGF, Ang-1, Ang-2), as well as platelet-derived growth factor (PDGF) and vasoactive hepatocyte growth factors $[36,38]$. Neovascularization generates delicate and permeable blood vessels that are conducive in vitreous hemorrhage. The repetition of such hemorrhages leads to the formation of fibrovascular scars and gliosis, the contraction of which prompts sight-threatening endpoints, namely, PDR and DME [37].

\section{Epidemiology}

Diabetes mellitus represents a set of metabolic diseases and, based on its mechanisms, it has been classified mainly into two categories, type 1 and type 2 diabetes. It is associated with a wide range of macrovascular and microvascular (retinopathy, neuropathy, nephropathy) complications [39]. A meta-analysis in 2010 revealed that DR caused the blindness and visual impairment of 0.8 million people out of 32.4 million blind people worldwide and 3.7 million individuals from a total of 191 million moderate-to-severely visually impaired (MSVI) people [40]. In 2015, these values elevated drastically; 36 million people were stated to be blind, $1.1 \%$ of which were due to DR. Moreover, DR contributed $1.3 \%$ to 216 million cases of visual impairment in 2015 [41]. It becomes more prevalent with the increasing severity and duration of diabetes [42,43]. According to a population-based study in southern Wisconsin among young type 1 diabetic patients, DR was found to be more prevalent in individuals with an onset of diabetes less than five years earlier (17\%), contrasted to those with cases of 15 years or more (97.5\%) [44]. Furthermore, the Diabetes Control and Complications Trial (DCCT)-EDIC (Epidemiology of Diabetes Interventions) study group recently carried out a 30-year-long follow-up study on type 1 diabetic individuals and estimated that individuals without DR are more susceptible to progression of visual impairment $(2.9 \%)$ than those with minor DR at baseline $(5.7 \%)[45,46]$. Another similar study discovered that the frequency of DR is higher among diabetic men as they are found to have a higher hemoglobin A1c level, a prolonged period of diabetes, greater systolic blood pressure, and frequent use of insulin [44]. A cross-sectional study in 1980 demonstrated that DR is more prevalent among type 1 diabetic patients below the age of $30(71 \%)$ compared to the older group suffering from type 2 diabetes (39\%) [5]. The most advanced complications of DR include DME and proliferative retinopathy (PR) [1,47]. According to a pooled individual meta-analysis from 1980 to 2008 among the working-class population (20-79 years), the prevalence of DR was $35 \%$, followed by PDR at $7.2 \%$, and DME at $7.5 \%$. Regardless of the duration of diabetes, these conditions were found to be more frequent among the insulin-dependent diabetes mellitus (IDDM) group than the non-insulin-dependent diabetes mellitus (NIDDM) group, such as DR (77\% vs. $32 \%)$, PDR (32\% vs. $3 \%$ ), and DME (14\% vs. 6\%) [2]. The Wisconsin Epidemiologic Study of Diabetic Retinopathy (WESDR) studied the prevalence of PDR and DME among three different groups-young individuals, old type 1 diabetic patients, and old type 2 diabetic patients. They found that PDR is the predominant complication [43] among the two, affecting $23 \%$, $10 \%$, and only $3 \%$ of individuals within each group, respectively [48]. In addition, the geographical region significantly contributes to the prevalence of diabetic retinopathy. It is widespread and sight-threatening among people from developing countries in Asia, Africa, Latin America, and of indigenous tribal descent, in contrast to the European population [49]. The South Asian countries India, Singapore, and China contribute the largest proportion of the annual DR incidence population (2.2-3.5\%) worldwide [45]. India and China are the most populous countries around the world, and within the last century, they have achieved exponential economic success. However, with this economic success came a significant change in their residents' lifestyles, which included unhealthy diets and reduced physical activity, which caused obesity, hypertension, and high cholesterol that further increased their DR disease burden. This Westernized lifestyle is more significant in urban areas in contrast to rural areas; therefore, DR is also found to be extensively prevalent in the more developed urban regions of both India and China. DR affects $18.0 \%$ and $10.3 \%$ of the type 2 diabetic population in the urban and rural regions of India, respectively. Parallel studies in China also demonstrated that both DR and VTDR (vision-threatening diabetic 
retinopathy) was less significantly prevalent within the type 2 diabetic population in the poorer regions compared to urban regions (27.6\% and $11.9 \%$ vs. $33.1 \%$ and $15.5 \%$ ), respectively. Interestingly, studies have also reported that differences in ethnicity contribute to the commonness of type $2 \mathrm{DM}$ but not to that of DR. A valid reason behind this difference has not been found yet but it is assumed that racial and cultural practices might have facilitated the risk factors for DM, such as alcohol consumption, cardiovascular disease prevalence, smoking, obesity, and hypertension, but not that of DR [41]. These data signify that diabetic retinopathy has become a global concern due to its increasing prevalence over the years worldwide [50] and therefore, the development of improved diagnostic, screening, and preventive strategies are highly crucial.

\section{Risk Factors of Diabetic Retinopathy}

DR is a persistent ocular fundus condition that accounts for $80 \%$ of visual loss in individuals with diabetes and therefore affects the quality of life, as well as elevating the financial burden on society [51,52]. Risk factors of diabetic retinopathy include its duration, the presence of diabetic nephropathy, neuropathy, foot ulcer and amputation, along with hypertension, the level of cholesterol and triglyceride in the serum, fasting blood glucose, the level of $\mathrm{HbA1c}$ and the age of the patient [53]. A study was carried out with 71 diabetic out-patients receiving insulin treatment who suffered from the illness for one to two decades, to determine the serum magnesium content. As per the extremity of retinopathy of the patients, they were split into two groups. Group A comprised patients having normal fundi or minimal alterations (microaneurysms and/or exudates smaller than microaneurysms), whereas group B included patients with more extreme abnormalities, including microaneurysms with larger hemorrhages and/or exudates, as well as proliferative retinopathy. Subjects as a whole had definite hypomagnesemia $(p<0.001)$, which was markedly evident among the segment with the most severe retinopathy $(p<0.01)$. In terms of established risk factors for DR, the segments were comparable. As a result, hypomagnesemia appeared to represent a new risk factor associated with the offset and development of the condition [54]. The course of diabetes and improper glycemia control (high $\mathrm{HbA1c}$ ), along with the presence of hypertension, are the most important risk factors for the development of diabetic retinopathy. Notably, blood glucose management has a greater impact on the possibility of diabetic retinopathy than blood pressure control [53]. According to the previous finding, hyperglycemia, blood pressure, dyslipidemia, and obesity are the most frequent modifiable risk factors for DR [41]. Serum lipids affect the progression of PDR or DME to a lesser extent in the case of hyperlipidemia and obesity. In reality, investigations on the influence of lipids on the growth and genesis of PDR and DME have provided mixed results [55]. Moreover, a complex and significant correlation was discovered amid glycemic control and alcohol intake. The progress of severe retinopathy (exudative and proliferative) was shown to be associated with excessive alcohol intake in 9 out of a total of 70 heavy drinkers $(13 \%)$ in contrast to the remaining ten $(4.4 \%)$. Alcohol intake might be a key independent factor in the development of diabetic retinopathy that threatens the sight [56]. Hyperglycemia is the most common cause of DM. The DCCT and The UK Prospective Diabetes Study (UKPDS) are two important clinical trials that have demonstrated strong linkages between blood glucose levels and the offset and advancement of DR. DCCT was released in 1993 and included data from 1441 type 1 diabetic patients from 1982 to 1993. In the course of the clinical trial, intense treatment of hyper glycemia reduced the incidence and progression of DR by 76\% and 54\%, respectively. Between 1977 and 1997, UKPDS looked at 5102 type 2 diabetic individuals and found that proper blood glucose management decreased DR by $25 \%$ in contrast to standard therapy. Furthermore, it was found that for every $1 \%$ drop in glycosylated hemoglobin (HbA1c), the progression of DR falls by $40 \%$, 25\% proceed to sight-threatening DR, 25\% require laser therapy, and $15 \%$ of diabetics go blind. It has recently been shown that keeping the $\mathrm{HbA1c}$ level lower than $7.6 \%$ (60 mmol $/ \mathrm{mol})$ can avoid PDR in type 1 diabetes patients for up to 20 years [55]. In another study conducted specifically on type 2 diabetic individuals, a significant pro- 
portional relationship was found to exist between obesity and the prevalence of diabetic retinopathy. A significant escalation $(p<0.05)$ was observed with an increase in body mass index (BMI). However, the proportionality of DR in association with other clinical and metabolic parameters such as hemoglobin, LDL (low-density lipoprotein)-cholesterol levels, and BP was observed [57]. One more pooled analysis carried out on individuals from population-based research around the globe also demonstrated a direct correlation of hypertension, along with other factors, with the occurrence of DR [58].

\subsection{Genetic Risk Factors of Retinopathy}

In accordance with various twin studies, DR is classified as a polygenic disorder that is genetically inherited, with researchers having discovered an obvious familial clustering. DR and PDR are found to be $27 \%$ and $52 \%$ heritable, respectively [59]. Studies have shown that a family history of DR increased the risk of DR among individuals by almost twoto three-fold [60]. The occurrence of diabetic retinopathy is also influenced by ethnicity according to the Multi-Ethnic Study of Atherosclerosis (MESA) which reported prevalence rates of $36.7 \%$ in African Americans, 37.4\% in Hispanics, $24.8 \%$ in whites, and $25.7 \%$ in Chinese-Americans [61]. A sub-linkage analysis for DR was conducted in Pima Indians among individuals with T2D (type 2 diabetes) and found a faint possibility of a linkage at chromosomes 3 and 9 with LOD (logarithm of the odds) scores of 1.36 and 1.46, respectively [62]. A genome-wide meta-analysis identified a close association between the intergenic SNP (single-nucleotide polymorphism) rs476141 and DR. However, the results were not consistent with the Wisconsin Epidemiologic Study of Diabetic Retinopathy, which instead identified that in the gene CEP125, an intronic SNP at rs4865047 has a potential linkage with DR [63]. Similarly, several linkage analyses, candidate gene association studies, and genome-wide association studies (GWAS) have proposed a few possible genetic variants such as the ALR2 (aldose reductase), VEGF and RAGE (receptor for advanced glycation end-products) genes. However, the loci which act as risk factors in DR have not yet been discovered $[59,61]$.

\subsection{Other Risk Factors}

Dyslipidemia, a high BMI, puberty, pregnancy, and cataract surgery are all risk factors for diabetic retinopathy [53]. In research conducted in Asia, BMI was shown to have a non-significant or negative relationship with DR. No proportional links were observed between DR and BMI in the study from China, but studies from South Korea and Singapore indicated a link between BMI and the occurrence of DR. Lower BMI might indicate a poorly-handled and severely complicated condition of diabetes that leads to DR and weight reduction; however, an elevated BMI can lead to a smaller duration for the milder stage of diabetes, reducing its prevalence [41]. Other research has shown that the amount of time spent viewing television is linked to aberrant retinal vascular signals on its own. The proportionality in these links is not accurate as a result of the lack measures in physical exercises, sedentary lifestyles, longitudinal data in studies, and because of studies dealing with only type 1 diabetes [64]. Diabetic retinopathy was found to be present in $17.6 \%$ of the population from rural areas who reported their illness themselves. Referable (sightthreatening) retinopathy was found in $5.3 \%$ of the population. Male gender $(\mathrm{OR}=1.37)$, a longer duration of diabetes (per year, $\mathrm{OR}=1.07)$, lean body mass index $(\mathrm{OR}=1.30)$, higher systolic blood pressure (per $10 \mathrm{~mm} \mathrm{Hg}, \mathrm{OR}=1.18$ ), and insulin treatment $(\mathrm{OR}=1.34$ ) were all linked with the development of any DR. The study discovered risk factors for DR in diabetics living in rural areas. The research suggested that effective preventative strategies were needed in rural regions to reduce avoidable blindness related to diabetes [65].

\section{Diagnosis and Management of Diabetic Retinopathy}

7.1. Diagnosis

Diabetic patients, along with their relatives, friends, and healthcare providers, must be informed about the significance of regular eye examinations to check for DR early [66]. 
Some of the diagnostic techniques that may be used to diagnose, identify, and examine DR, as well as the efficacy of treatment, are direct and indirect ophthalmoscopy, stereoscopic digital and Fundus photography, mydriatic or nonmydriatic digital color or monochromatic single-field photography, ultrawide-field fundus fluorescein angiography (UWFA), optic coherence tomography (OCT), and optic coherence tomography-angiography (OCT-A), as well as fluorescein angiography [66-69]. The most common method of diagnosis of diabetic retinopathy is ophthalmoscopy. However, compared to stereoscopic seven-field color photography, un-dilated ophthalmoscopy has low sensitivity, especially when performed by practitioners not involved with eye care. Direct ophthalmoscopy, when performed by non-ophthalmologists, can detect approximately $50 \%$ of cases of proliferative retinopathy under normal clinical situations [67]. The Early Treatment Diabetic Retinopathy Study (ETDRS) group certified the grading of stereoscopic color fundus photographs in seven standard fields (SSFs) as a recognized standard for the diagnosis of DR. Although this method is precise and repeatable, it requires the use of professional photographers and photo readers, as well as advanced photographic equipment, film processing, and archiving. A diabetic retinopathy diagnosis methodology on the basis of single-field fundus photography has also been used. Patients with type 1 or type 2 diabetes were photographed consecutively through a non-pharmacologically dilated pupil using single-field digital monochromatic non-mydriatic photography (SNMDP), and then pharmacologically dilated before being examined by an ophthalmologist using ophthalmoscopy and having $30^{\circ}$ color stereoscopic photographs taken in SSFs. However, comparative studies that were well planned have shown that single-field fundus photography may be used as an early diagnostic technique for diabetic retinopathy, detecting individuals with retinopathy and recommending them for ophthalmic diagnosis and care [67]. The ETDRS group introduced the standard seven-field stereoscopic fundus photographs for diagnosis of the severity of diabetic retinopathy [70]. Fundus photography was used to obtain a new record; therefore, it is recommended methodology for evaluating retinopathy [66,70]. One of the most notable developments in the last decade has been the increasing use of ultrawide-field fundus fluorescein angiography (UWFA) and OCT in DR for diagnosis. The UWFA captures up to $200^{\circ}$ of the peripheral retinas in just one frame. According to recent research, it can be used to view 3.2-times the amount of retinal surface area in contrast to the conventional seven standard fields. In comparison to the typical seven standard fields, UWFA was found to image 3.9 times more nonperfusion, 1.9 times more neovascularization, and 3.8 times more pan-retinal photocoagulation. Its utilization for better imaging of the retinal periphery may have significant implications for the management of DR in patients [68]. Moreover, in the diagnosis of DR, fluorescein angiography and OCT are even used by ophthalmologists to examine the permeability (leakage) and thickness of the blood vessels in the retina. Advanced technologies, such as OCT angiography, are also growing in popularity [69]. Since its emergence, OCT has transformed clinical imaging for assessment and disease control in most retinal disorders, including DME [71]. It is a non-invasive imaging method for obtaining high-resolution cross-sectional pictures of the retina, the retinal nerve fiber layer, and the optic nerve head [68]. The current third-generation optic coherence tomography (OCT) technology utilizes a swept-source (SS) light source to produce three-dimensional raster photographs with a great microstructural resolution, commonly known as optical histology [71]. Optical coherence tomography angiography (OCT-A), a recent advancement, has revolutionized the ability of professionals to investigate the complex vasculature of the retina without the usage of a contrast dye [70]. OCT-A is a non-invasive diagnostic technique that generates images that resemble angiographic pictures using motion contrast imaging. It produces a very detailed view of the retina vasculature, allowing accurate delineation of the foveal avascular zone (FAZ) and the diagnosis of minor microvascular anomalies such as FAZ extension, capillary non-perfusion areas, and intraretinal cystic spaces. The capability to detect microvascular alterations in diabetic eyes prior to the appearance of apparent microaneurysms might have far-reaching ramifications in the future [66]. Fluorescein angiography is an invasive, expensive, and 
time-consuming procedure for detecting vascular changes caused by the rupture of the inner and outer blood-retinal barrier in DR. However, the retinal vasculature may be seen with great precision, allowing the examiner to spot small microaneurysms and distinguish between them (hyperfluorescent) and punctiform hemorrhages (hypo-fluorescence due to the masking effect). It is an indispensable investigation before deciding on laser therapy, such as, to distinguish ischemic retinal edema from leakage, which turns white following the accumulation of dye (hypo-fluorescent). The use of laser effects in this circumstance is not suggested since it increases retinal ischemia [66].

\subsection{Management}

Interventions fall into the three following categories to minimize the risk of vision loss due to DR: the primary prevention of microvascular problems, the early identification of retinopathy, and the effective treatment of existing disease [72]. Blood glucose and blood pressure regulation must be strictly observed to confine the rate and progression of DR [73]. Some randomized controlled studies have shown that blood pressure regulation is an independent risk factor for DR outcomes. According to the EDIC research, each $5 \mathrm{mmHg}$ rise in mean blood pressure $(p<0.001)$ increased the probability of DR by $11 \%$. Despite the fact that the exact significance of blood pressure regulation in diabetes patients optimal ocular outcomes is unclear, strict blood pressure control should be encouraged [74]. Diabetes treatment, guided by blood glucose measurements, reduces the occurrence and development of DR in both type 1 and type 2 diabetes, respectively. The severity of diabetes mellitus (DM) is proportional to the mean glycated hemoglobin index (HbA1c), and strict glucose management provides long-term advantages in delaying or avoiding DM, even when subsequent control is lax [75]. Ophthalmic randomized controlled trials (RCT) validated that blood pressure management and strict glycemic control is a key modifiable factor that can decrease the incidence and development of DR. Pan-retinal laser photocoagulation (PRP), which includes laser burns placed over the whole retina, excluding the central macula, is an established method for treating severe non- proliferative and proliferative DR [76]. In individuals with severe non-proliferative and proliferative retinopathy, pan-retinal laser photocoagulation lowers the probability of moderate and severe vision loss by 50 percent [76,77]. Treatments for clinically prominent diabetic macular edema have been found to be an efficient therapy, utilizing focal or grid laser photocoagulation, as determined by the Early Treatment Diabetic Retinopathy Study group based on clinical fundus examination [78]. There is significant proof that focal laser photocoagulation lowers the risk of mild vision loss by $50 \%$ to $70 \%$ and increases the possibility of visual improvement $[76,77]$. Some retinal experts have claimed that vasogenic antagonism might completely replace laser photocoagulation, citing new results. However, because of its long-term advantages, this medication remains a significant element of the DR therapeutic arsenal. Macular photocoagulation is more likely to give similar results to those of peripheral pan-retinal photocoagulation (PRP), i.e., by ablating ischemic retinal tissue to diminish VEGF release from hypoxic sources. Since the pioneering research of ETDRS and the Diabetic Retinopathy Study (DRS), photocoagulation has remained a foundation of DR therapy. These treatments have been related to nyctalopia, presbyopia, and laser scotoma, as well as a decrease in the peripheral field [75]. The flow chart represents some of the current therapeutic techniques of DR along with their limitations and drawbacks are shown below (Figure 3). 


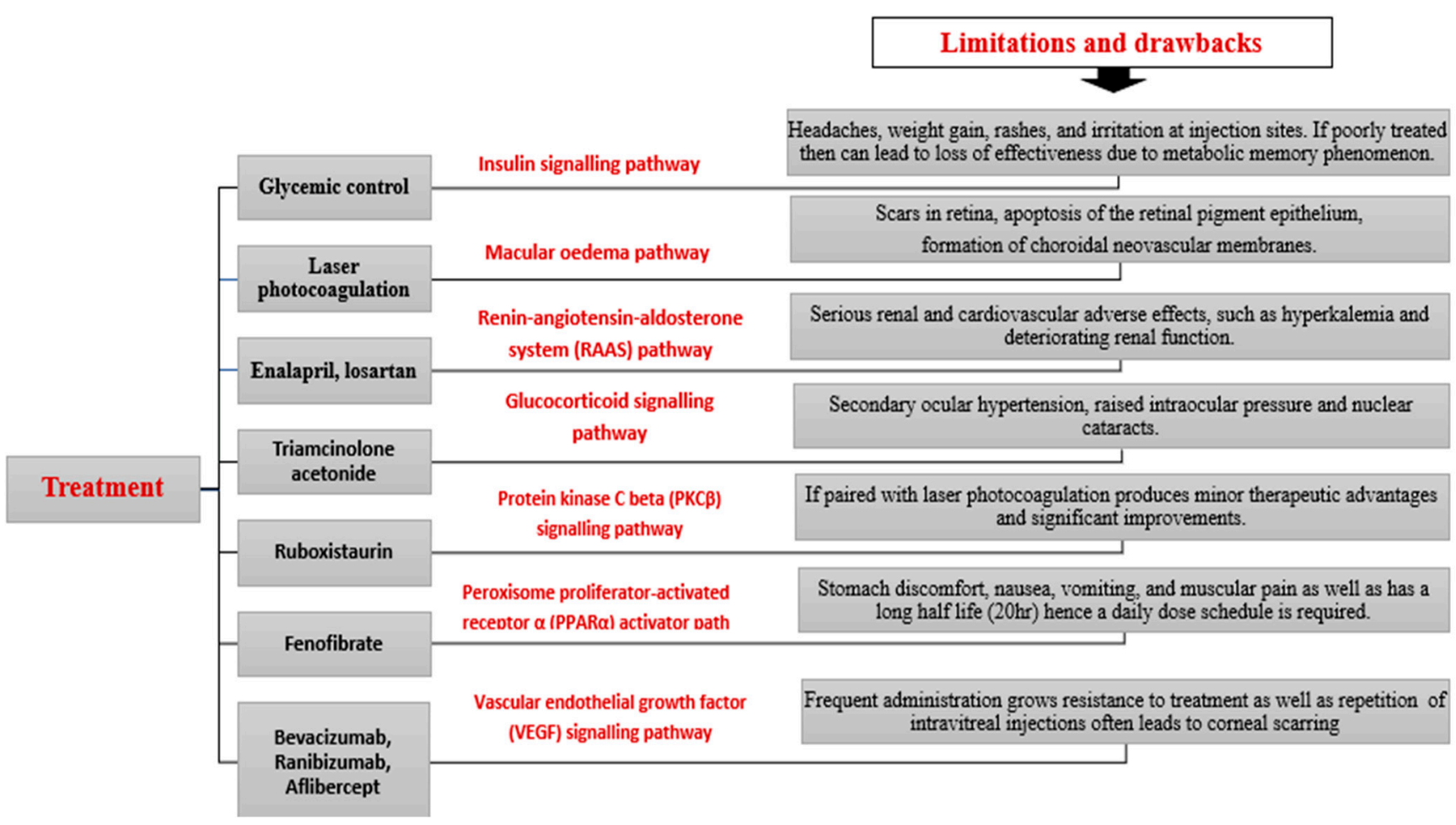

Figure 3. Summary of the current therapeutic techniques for diabetic retinopathy (DR) management, including their limitations and drawbacks [69].

The effects of the angiotensin-converting enzyme (ACE) inhibitor enalapril on the development of DR were compared with those of the angiotensin II receptor type 1 inhibitor losartan in one study. The mechanisms of these two medications for suppressing the renin angiotensin aldosterone system (RAAS) have no statistically significant variation, suggesting that they are both equally effective. Furthermore, in diabetic retinopathy-naive and moderate diabetic retinopathy caused by type 1 diabetes mellitus, the use of candesartan cilexetil, an angiotensin-II receptor inhibitor, was demonstrated to decrease the progression of the condition. However, in human clinical trials, the research group identified very minor improvements in vision loss, and the impact of ruboxistaurin, a protein kinase $C-\beta$ (PKC- $\beta$ )-specific inhibitor, was only significant when paired with laser photocoagulation [69]. Although early research shows that treating diabetic patients with ruboxistaurin, a protein kinase C- $\beta$ (PKC- $\beta$ )-specific inhibitor, may improve vision loss in DR patients [79]. Although the latest evidence indicates that fenofibrate treatment reduces the chance of DR onset and progression in type 2 diabetic patients, the mechanism by which this arises seems to be independent of the reduction in systemic high-density lipid and mean triglyceride levels seen in the FIELD and clinical trials [69]. Somatostatin (SST) is an endogenous cyclic tetra decapeptide hormone that is produced by the retina, with the retinal pigment epithelium (RPE) being the primary source in the human eye [80]. Somatostatin receptors are the targets of somatostatin analogues such as octreotide, which are proven to be very effective in the treatment of DR and DME [81]. The use of anti-vascular endothelial growth factor (A-VEGF) medications such as bevacizumab, ranibizumab, and pegaptanib in the treatment of DR was examined in recent research. The effect of ranibizumab in diabetic macular edema has only been studied in one major randomized controlled study [82]. Ranibizumab is a 48-kDa fragment of an antibody that targets all isoforms of human A-VEGF and has a higher binding affinity and shorter systemic half-life than bevacizumab, a filled recombinant humanized A-VEGF antibody that was first used to treat colon cancer. The RISE (clinicaltrials.gov ID: NCT00473330) and RIDE (clinicaltrials.gov ID: NCT00473382) trials, which contrasted ranibizumab 0.3 or $0.5 \mathrm{mg}$ to sham therapy on a monthly basis, were pivotal in the use of ranibizumab for DME [83]. The use of bevacizumab for the treatment of 
DR without DME is based on a small body of data. For the treatment of clinically significant macular edema (CSME), the BOLT (bevacizumab or laser therapy) study compared bevacizumab to macular laser (MLT) [83]. The VISTA (clinicaltrials.gov ID: NCT01363440) and VIVID (clinicaltrials.gov ID: NCT01331681) studies resulted in the approval of aflibercept for the treatment of DME. Aflibercept $2 \mathrm{mg}$ administered every 4 weeks and aflibercept 2 mg every 8 weeks following 5 monthly doses, and focal/grid laser were also tested in these trials. From baseline to three years, baseline eyesight increased by 10.5 letters, 10.4 letters, and 1.4 letters $(p<0.0001)$. The most prevalent significant ocular adverse event recorded was cataract. Both aflibercept groups had three times the chance of improving their DRSS (Diabetic Retinopathy Severity Scale) score by at least two steps [83]. Inflammation is a major factor in DR; thus, corticosteroids are used in the treatment of DR, specifically DME. When paired with focused laser photocoagulation, landmark research from the Diabetic Retinopathy Clinical Research Network (DRCR.net) evaluated the effectiveness of intravitreous triamcinolone in a center involving DME [75]. The schematic diagram shows the current treatments of DME along with their mechanism of action, route of administration as well as the frequency of administration (Figure 4).

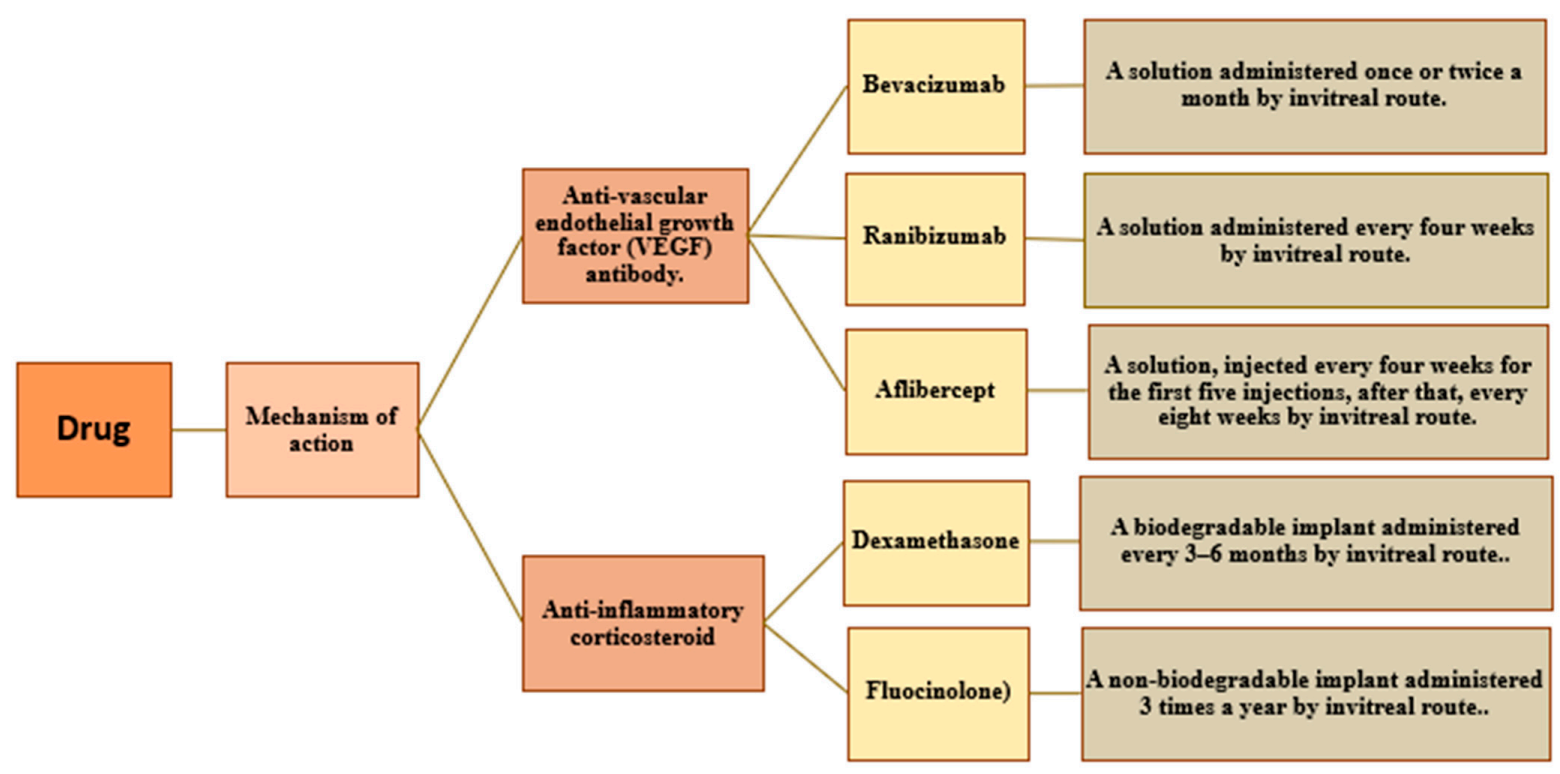

Figure 4. Summary of the treatments for diabetic macular edema that are currently available in the market [80].

In addition, anti-VEGF medicines, other anti-angiogenic medications such as squalamine are now being studied in clinical trials (Figure 5). Squalamine inhibited various angiogenic factors, such as VEGF, platelet-derived growth factor (PDGF), and basic fibroblast growth factor (b-FGF), resulting in an improved visual recovery in patients with macular edema than control groups. A clinical investigation evaluating the effects of squalamine in conjunction with ranibizumab in DME patients is now underway (clinicaltrials.gov ID: NCT02349516). Novel drugs have also been identified that target participants in the angiopoietin-Tie2 signaling pathway. AKB-9778 is a small molecule that inhibits the Tie2 via vascular endothelial-protein tyrosine phosphatase (VE-PTP), a negative regulator, causing Tie2 activation and decrease the vascular permeability (Figure 6). AKB-9778 is now under clinical trial for the treatment of DME (NCT01702441). Nesvacumab is an anti-Ang-2 monoclonal antibody that works by activating Tie2 and hence reduce the vascular permeability (Figure 6). In a phase 2 trial, nesvacumab combined with the VEGF inhibitor aflibercept is being explored in DME patients (RUBY study, clinicaltrials.gov ID: NCT02712008). Another bispecific antibody, RO6867461, is being tested in DME patients. It targets both Ang-2 and VEGF (BOULEVARD study, clinicaltrials.gov ID: NCT02699450) [10]. The flow chart 
indicates some of the Anti-angiogenic drugs for the treatment of diabetic retinopathy along with their clinical benefits and adverse effects (Figure 5).

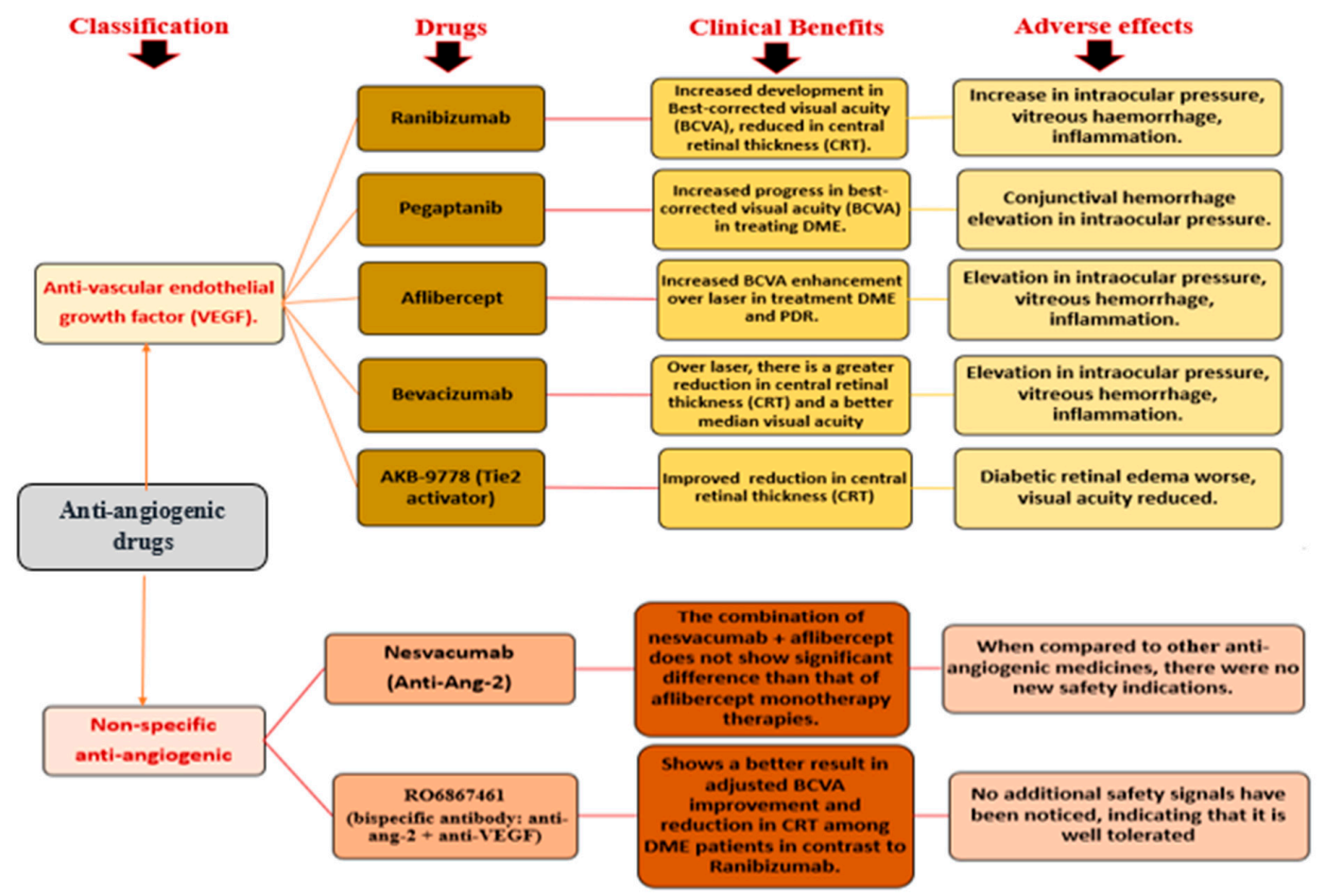

Figure 5. Anti-angiogenic drugs for the treatment of diabetic retinopathy (DR) [10].

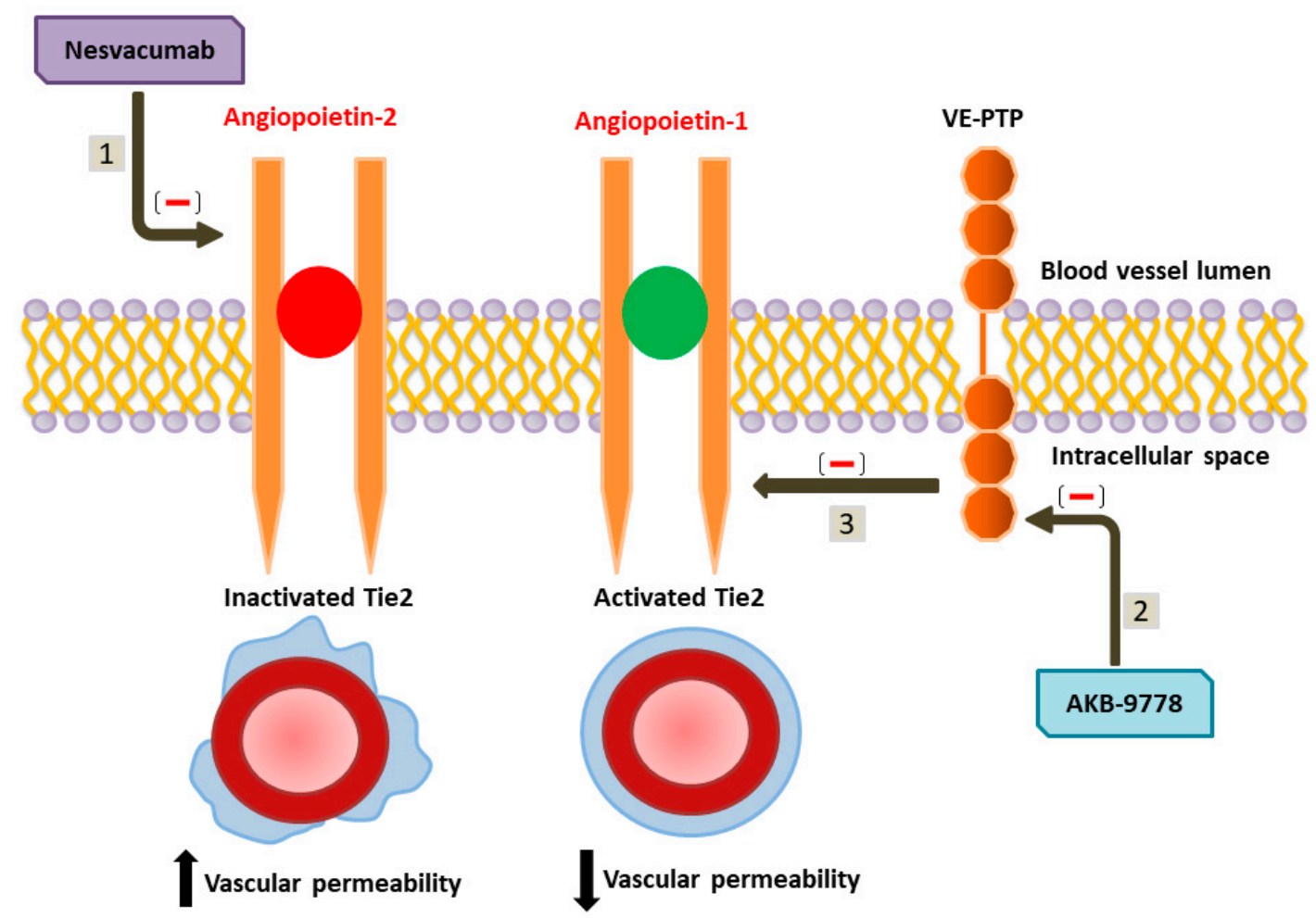

Figure 6. (1) Nesvacumab stimulates Tie-2 signaling and suppresses vascular permeability by inhibiting Ang-2, a Tie-2 antagonist. (2) AKB-9778 stimulates Tie-2 signaling by inhibiting (3) a Tie-2 negative regulator, VE-PTP [10]. 


\section{Pharmacological Targets and Future Perspectives}

Diabetic retinopathy can be treated pharmacologically in multiple ways. High blood glucose levels cause significant changes in cellular metabolisms, such as endothelial dysfunction, which starts the morphological process of diabetic retinopathy [84]. Many diabetic patients suffer from DR, which can lead to a variety of other serious illnesses, requiring laser photocoagulation treatment, as well as the management of blood glucose levels and blood pressure [85]. Pharmacologically, the metabolic damage caused by chronic hyperglycemia can be significantly impacted, although not necessarily restored, with various medication groups now under development. As a result, tight glycemic management, together with an effective ophthalmologic detection and follow-up program in diabetic patients, is a critical step in avoiding the onset or progression of DR. Antiplatelet drugs have been shown to slow the evolution of diabetic retinopathy in its early stages, including a decreased degree of microaneurysms, suggesting that endothelial dysfunction is implicated. However, a novel strategy for regulating endothelial dysfunction, mostly through the use of VEGF inhibitors, appears to be promising. These drugs might be particularly beneficial in the treatment of PDR. Antioxidant medicines and inhibitors of the development of advanced glycation end-products have also had positive outcomes [84]. Along with significant financial and societal consequences, DR affects patients psychologically as well. Taking this into account, scientists are working hard to develop therapy for DR. The polyol pathway, advanced glycation end-products, protein kinase $C$, and oxidative stress have all been implicated in the development of DR, and numerous therapeutic studies have also been undertaken to assess the effectiveness of various medications. Recent results also show that DR has features related with chronic inflammatory and neurological disease, increasing the possibility of pharmaceutical management [85].

Due to its multifactorial nature, DR is a complicated ocular condition. The main therapeutic challenge is to find a medication that can target several pathways implicated in DR development. DR can be categorized as the vascular degeneration of the retina and mitochondrial dysfunction. The restoration of mitochondrial activity and normalization of vascular degeneration is a viable therapeutic strategy for managing disease progression. Continued studies in this area will certainly yield new insights into the prevention and treatment of DR [86].

\section{Conclusions}

The possibility of occurrence of diabetic retinopathy in individuals continues to escalate at a significant rate. However, research is ongoing to apprehend the underlying pathophysiology. This review discusses several mechanisms and prospective therapeutic targets to intervene in retinopathy progression. Despite a few limitations, the current management of DR, including glycemic control, control in blood pressure levels, use of anti-inflammatory corticosteroids, and focal laser treatment, have proven to be beneficial in the preceding research. Nevertheless, medications such as AGE inhibitors, antiplatelet and antioxidant medicines, and others have shown potential as well. Further research is required to overcome the drawbacks and develop effective treatments with reduced side effects.

Author Contributions: Conceptualization, P.A. and S.A.; formal Analysis, P.A. and N.N.S.; funding acquisition, P.A. and J.M.A.H.; investigation, resources, writing, and editing, P.A., N.N.S., N.H.S., N.T. and R.V.N.R.S.P.; supervision and reviewing, P.A. and Y.H.A.A.-W. All authors have read and agreed to the published version of the manuscript.

Funding: This research received no external funding.

Institutional Review Board Statement: Not Applicable.

Informed Consent Statement: Not Applicable.

Data Availability Statement: Not Applicable. 
Conflicts of Interest: The authors declare no conflict of interest.

\section{References}

1. Maurya, R.P. Diabetic retinopathy: My brief synopsis. Indian J. Clin. Exp. Ophthalmol. 2015, 1, 189-190.

2. Song, P.; Yu, J.; Chan, K.Y.; Theodoratou, E.; Rudan, I. Prevalence, risk factors and burden of diabetic retinopathy in China: A systematic review and meta-analysis. J. Glob. Health 2018, 8, 010803. [CrossRef] [PubMed]

3. Watkins, P.J. Retinopathy. Br. Med. J. 2003, 326, 924-926. [CrossRef] [PubMed]

4. Fowler, M.J. Microvascular and macrovascular complications of diabetes. Clin. Diabetes 2008, 26, 77-82. [CrossRef]

5. Porta, M.; Bandello, F. Diabetic retinopathy. Diabetologia 2002, 45, 1617-1634. [CrossRef]

6. Fong, D.S.; Aiello, L.; Gardner, T.W.; King, G.L.; Blankenship, G.; Cavallerano, J.D.; Ferris, F.L.; Klein, R. Retinopathy in diabetes. Diabetes Care 2004, 27, s84-s87. [CrossRef]

7. Stitt, A.W.; Curtis, T.M.; Chen, M.; Medina, R.J.; McKay, G.J.; Jenkins, A.; Gardiner, T.A.; Lyons, T.J.; Hammes, H.P.; Simo, R.; et al. The progress in understanding and treatment of diabetic retinopathy. Prog. Retin. Eye Res. 2016, 51, 156-186. [CrossRef] [PubMed]

8. Raman, R.; Gella, L.; Srinivasan, S.; Sharma, T. Diabetic retinopathy: An epidemic at home and around the world. Indian J. Ophthalmol. 2016, 64, 69. [CrossRef]

9. Aiello, L.M. Perspectives on diabetic retinopathy. Am. J. Ophthalmol. 2003, 136, 122-135. [CrossRef]

10. Wang, W.; Lo, A. Diabetic Retinopathy: Pathophysiology and Treatments. Int. J. Mol. Sci. 2018, 19, 1816. [CrossRef]

11. Madsen-Bouterse, S.A.; Kowluru, R.A. Oxidative stress and diabetic retinopathy: Pathophysiological mechanisms and treatment perspectives. Rev. Endocr. Metab. Disord. 2008, 9, 315-327. [CrossRef] [PubMed]

12. Duh, E.J.; Sun, J.K.; Stitt, A.W. Diabetic retinopathy: Current understanding, mechanisms, and treatment strategies. J. Clin. Investig. 2017, 2, e93751. [CrossRef] [PubMed]

13. Shani, M.; Eviatar, T.; Komaneshter, D.; Vinker, S. Diabetic Retinopathy -Incidence and Risk Factors in A Community Setting- A Longitudinal Study. Scand. J. Prim. Health Care 2018, 36, 237-241. [CrossRef] [PubMed]

14. Davidson, J.A.; Ciulla, T.A.; McGill, J.B.; Kles, K.A.; Anderson, P.W. How the diabetic eye loses vision. Endocrine 2007, 32, 107-116. [CrossRef]

15. Ola, M.S.; Nawaz, M.I.; Siddiquei, M.M.; Al-Amro, S.; Abu El-Asrar, A.M. Recent advances in understanding the biochemical and molecular mechanism of diabetic retinopathy. J. Diabetes Complicat. 2012, 26, 56-64. [CrossRef]

16. Yamagishi, S.; Matsui, T.; Inoue, H. Inhibition by advanced glycation end products (AGEs) of pigment epithelium-derived factor (PEDF) gene expression in microvascular endothelial cells. Drugs Exp. Clin. Res. 2005, 31, 227-232.

17. Yamagishi, S.; Matsui, T.; Nakamura, K.; Takeuchi, M.; Imaizumi, T. Pigment epithelium-derived factor (PEDF) prevents diabetesor advanced glycation end products (AGE)-elicited retinal leukocytosis. Microvasc. Res. 2006, 72, 86-90. [CrossRef]

18. Yamagishi, S.; Matsui, T. Advanced Glycation End Products (AGEs), Oxidative Stress and Diabetic Retinopathy. Curr. Pharm. Biotechnol. 2011, 12, 362-368. [CrossRef]

19. Ibrahim, A.S.; El-Remessy, A.B.; Matragoon, S.; Zhang, W.; Patel, Y.; Khan, S.; Al Gayyer, M.M.; El-Shishtawy, M.M.; Liou, G.I. Retinal Microglial Activation and Inflammation Induced by Amadori-Glycated Albumin in a Rat Model of Diabetes. Diabetes 2011, 60, 1122-1133. [CrossRef]

20. Calderon, G.; Juarez, O.; Hernandez, G.; Punzo, S.; De la Cruz, Z. Oxidative stress and diabetic retinopathy: Development and treatment. Eye 2007, 31, 1122-1130. [CrossRef] [PubMed]

21. Lorenzi, M. The Polyol Pathway as a Mechanism for Diabetic Retinopathy: Attractive, Elusive, and Resilient. Exp. Diabetes Res. 2007, 2007, 1-10. [CrossRef] [PubMed]

22. Van den Enden, M.K.; Nyengaard, J.R.; Ostrow, E.; Burgan, J.H.; Williamson, J.R. Elevated glucose levels increase retinal glycolysis and sorbitol pathway metabolism, Implications for diabetic retinopathy. Investig. Ophthalmol. Vis. Sci. 1995, 36, 1675-1685.

23. Steinmetz, P.R.; Balko, C.; Gabbay, K.H. The Sorbitol Pathway and the Complications of Diabetes. N. Engl. J. Med. 1973, 288, 831-836. [CrossRef] [PubMed]

24. Szwergold, B.; Kappler, F.; Brown, T. Identification of fructose 3-phosphate in the lens of diabetic rats. Science 1990, 247, 451-454. [CrossRef]

25. Gonzalez, R.G.; Miglior, S.; Von Saltza, I.; Buckley, L.; Neuringer, J.; Cheng, H.-M. 31P NMR studies of the diabetic lens. Magn. Reson. Med. 1988, 435-444. [CrossRef]

26. Ido, Y.; Kilo, C.; Williamson, J.R. Cytosolic NADH/NAD+, free radicals, and vascular dysfunction in early diabetes mellitus. Diabetologia 1997, 40, S115-S117. [CrossRef]

27. Drel, V.R.; Xu, W.; Zhang, J.; Kador, P.F.; Ali, T.K.; Shin, J.; Julius, U.; Slusher, B.; El-Remessy, A.B.; Obrosova, I.G. Poly (ADPRibose) Polymerase Inhibition Counteracts Cataract Formation and Early Retinal Changes in Streptozotocin-Diabetic Rats. Investig. Ophthalmol. Vis. Sci. 2009, 50, 1778. [CrossRef]

28. Engerman, R.L.; Kern, T.S. Hyperglycemia as a cause of diabetic retinopathy. Metabolism 1986, 35, 20-23. [CrossRef]

29. Holman, R.R.; Paul, S.K.; Bethel, M.A.; Matthews, D.R.; Neil, H.A.W. 10-year follow-up of intensive glucose control in type 2 diabetes. N. Engl. J. Med. 2008, 359, 1577-1589. [CrossRef]

30. Reiter, C. Functions of insulin and insulin receptor signaling in retina: Possible implications for diabetic retinopathy. Prog. Retin. Eye Res. 2003, 22, 545-562. [CrossRef]

31. Ferguson, T.A.; Griffith, T.S. A vision of cell death: Insights into immune privilege. Immunol. Rev. 1997, 156, 167-184. [CrossRef] 
32. James, C.R.; Cotlier, E. Fate of insulin in the retina: An autoradiographic study. Br. J. Ophthalmol. 1983, 67, 80-88. [CrossRef]

33. Folli, F.; Bonfanti, L.; Renard, E.; Kahn, C.; Merighi, A. Insulin receptor substrate-1 (IRS-1) distribution in the rat central nervous system. J. Neurosci. 1994, 14, 6412-6422. [CrossRef]

34. Baskin, D.G.; Sipols, A.J.; Schwartz, M.W.; White, M.F. Immunocytochemical detection of insulin receptor substrate-1 (IRS-1) in rat brain: Colocalization with phosphotyrosine. Regul. Pept. 1993, 48, 257-266. [CrossRef]

35. Zetterstrom, C.; Benjamin, A.; Rosenzweig, S.A. Differential Expression of Retinal Insulin Receptors in STZ-Induced Diabetic Rats. Diabetes 1992, 41, 818-825. [CrossRef]

36. Gardner, T.W.; Antonetti, D.A.; Barber, A.J.; Lanoue, K.F.; Nakamura, M. New insights into the pathophysiology of diabetic retinopathy: Potential cell-specific therapeutic targets. Diabetes Technol. Ther. 2000, 2, 601-608. [CrossRef]

37. Lechner, J.; O'Leary, O.E.; Stitt, A.W. The pathology associated with diabetic retinopathy. Vis. Res. 2017, 139, 7-14. [CrossRef]

38. Ciulla, T.A.; Amador, A.G.; Zinman, B. Diabetic retinopathy and diabetic macular edema: Pathophysiology, screening, and novel therapies. Diabetes Care 2003, 26, 2653-2664. [CrossRef]

39. American Diabetes Association. Diagnosis and classification of diabetes mellitus. Diabetes Care 2010, 33, S62-S69. [CrossRef]

40. Jonas, J.B.; Sabanayagam, C. Epidemiology and Risk Factors for Diabetic Retinopathy. Front. Diabetes 2019, 27, 20-37. [CrossRef]

41. Chua, J.; Lim, C.X.Y.; Wong, T.Y.; Sabanayagam, C. Diabetic retinopathy in the Asia-Pacific. Asia-Pac. J. Ophthalmol. 2018, 7, 3-16. [CrossRef]

42. Ding, J.; Wong, T.Y. Current epidemiology of diabetic retinopathy and diabetic macular edema. Curr. Diabetes Rep. 2012, 12, 346-354. [CrossRef]

43. Klein, R. The epidemiology of diabetic retinopathy: Findings from the Wisconsin Epidemiologic Study of Diabetic Retinopathy. Int. Ophthalmol. Clin. 1987, 27, 230-238. [CrossRef]

44. Klein, R.; Klein, B.E.; Moss, S.E.; Davis, M.D.; DeMets, D.L. The Wisconsin Epidemiologic Study of Diabetic Retinopathy: II. Prevalence and risk of diabetic retinopathy when age at diagnosis is less than 30 years. Achieves Ophthalmol. 1984, 102, 520-526. [CrossRef]

45. Sabanayagam, C.; Banu, R.; Chee, M.L.; Lee, R.; Wang, Y.X.; Tan, G.; Jonas, J.B.; Lamoureux, E.L.; Cheng, C.Y.; Klein, B.E.; et al. Incidence and progression of diabetic retinopathy: A systematic review. Lancet Diabetes Endocrinol. 2019, 7, 140-149. [CrossRef]

46. Zhang, X.; Saaddine, J.B.; Chou, C.F.; Cotch, M.F.; Cheng, Y.J.; Geiss, L.S.; Gregg, E.W.; Albright, A.L.; Klein, B.E.; Klein, R. Prevalence of diabetic retinopathy in the United States, 2005-2008. J. Am. Med. Assoc. 2010, 304, 649-656. [CrossRef]

47. Dwyer, M.S.; Melton, L.J.; Ballard, D.J.; Palumbo, P.J.; Trautmann, J.C.; Chu, C.P. Incidence of diabetic retinopathy and blindness: A population-based study in Rochester, Minnesota. Diabetes Care 1985, 8, 316-322. [CrossRef]

48. Klein, R.; Klein, B.E.; Moss, S.E. Epidemiology of proliferative diabetic retinopathy. Diabetes Care 1992, 15, 1875-1891. [CrossRef]

49. Sivaprasad, S.; Gupta, B.; Crosby-Nwaobi, R.; Evans, J. Prevalence of diabetic retinopathy in various ethnic groups: A worldwide perspective. Surv. Ophthalmol. 2012, 57, 347-370. [CrossRef]

50. Sabanayagam, C.; Yip, W.; Ting, D.S.; Tan, G.; Wong, T.Y. Ten emerging trends in the epidemiology of diabetic retinopathy. Ophthalmic Epidemiol. 2016, 23, 209-222. [CrossRef]

51. Liu, Y.; Yang, J.; Tao, L.; Lv, H.; Jiang, X.; Zhang, M.; Li, X. Risk factors of diabetic retinopathy and sight-threatening diabetic retinopathy: A cross-sectional study of 13,473 patients with type 2 diabetes mellitus in mainland China. Br. Med. J. 2017, 7, e016280. [CrossRef]

52. Matuszewski, W.; Stefanowicz-Rutkowska, M.M.; Szychlińska, M.; Bandurska-Stankiewicz, E. Differences in Risk Factors for Diabetic Retinopathy in Type 1 and Type 2 Diabetes Mellitus Patients in North-East Poland. Medicine 2020, 56, 177. [CrossRef]

53. Vujosevic, S.; Aldington, S.J.; Silva, P.; Hernández, C.; Scanlon, P.; Peto, T.; Simó, R. Screening for diabetic retinopathy: New perspectives and challenges. Lancet Diabetes Endocrinol. 2020, 8, 337-347. [CrossRef]

54. McNair, P.; Christiansen, C.; Madsbad, S.; Lauritzen, E.; Faber, O.; Binder, C.; Transbøl, I. Hypomagnesemia, a Risk Factor in Diabetic Retinopathy. Diabetes 1978, 27, 1075-1077. [CrossRef]

55. Rodríguez, M.L.; Pérez, S.; Mena-Mollá, S.; Desco, M.C.; Ortega, Á.L. Oxidative Stress and Microvascular Alterations in Diabetic Retinopathy: Future Therapies. Oxidative Med. Cell. Longev. 2019, 2019, 1-18. [CrossRef]

56. Young, R.J.; McCulloch, D.K.; Prescott, R.J.; Clarke, B.F. Alcohol: Another risk factor for diabetic retinopathy. Br. Med. J. 1984, 288, 1035-1037. [CrossRef]

57. Katušić, D.; Tomić, M.; Jukić, T.; Kordić, R.; Šikić, J.; Vukojević, N.; Šarić, B. Obesity-A risk factor for diabetic retinopathy in type 2 diabetes. Coll. Antropol. 2005, 29, 47-50.

58. Yau, J.W.Y.; Rogers, S.L.; Kawasaki, R.; Lamoureux, E.L.; Kowalski, J.W.; Bek, T.; Chen, S.J.; Dekker, J.M.; Fletcher, A.; Grauslund, J.; et al. Global Prevalence and Major Risk Factors of Diabetic Retinopathy. Diabetes Care 2012, 35, 556-564. [CrossRef]

59. Cho, H.; Sobrin, L. Genetics of diabetic retinopathy. Curr. Diabetes Rep. 2014, 14, 515. [CrossRef]

60. Leslie, R.D.; Pyke, D.A. Diabetic retinopathy in identical twins. Diabetes 1982, 31, 19-21. [CrossRef]

61. Wong, T.Y.; Klein, R.; Islam, F.A.; Cotch, M.F.; Folsom, A.R.; Klein, B.E.; Sharrett, A.R.; Shea, S. Multi-Ethnic Study of Atherosclerosis (MESA. Diabetic retinopathy in a multi-ethnic cohort in the United States. Am. J. Ophthalmol. 2006, 141, 446-455. [CrossRef]

62. Liew, G.; Klein, R.; Wong, T.Y. The role of genetics in susceptibility to diabetic retinopathy. Int. Ophthalmol. Clin. 2009, 49, 35. [CrossRef]

63. Simó-Servat, O.; Hernández, C.; Simo, R. Genetics in diabetic retinopathy: Current concepts and new insights. Curr. Genom. 2013, 14, 289-299. [CrossRef] 
64. Dirani., M.; Crowston, J.G.; Wijngaarden, P. Physical inactivity as a risk factor for diabetic retinopathy. A review. Clin. Exp. Ophthalmol. 2014, 42, 574-581. [CrossRef]

65. Sharma, T.; Rani, P.; Raman, R.; Chandrakantan, A.; Pal, S.; Perumal, G. Risk factors for diabetic retinopathy in self-reported rural population with diabetes. J. Postgrad. Med. 2009, 55, 92. [CrossRef]

66. Dascalu, A.M.; Serban, D.; Papanas, N.; Kempler, P.; Rizzo, M.; Stana, D.; Roman, G.; Pantea-Stoian, A. Type 2 Diabetes-From Pathophysiology to Cyber Systems; IntechOpen: London, UK, 2021; Chapter 10; p. 249. [CrossRef]

67. Fong, D.S.; Aiello, L.P.; Ferris, F.L.; Klein, R. Diabetic Retinopathy. Diabetes Care 2004, 27, 2540-2553. [CrossRef]

68. Song, S.J.; Wong, T.Y. Current Concepts in Diabetic Retinopathy. Diabetes Metab. J. 2014, 38, 416. [CrossRef]

69. Whitehead, M.; Wickremasinghe, S.; Osborne, A.; Van Wijngaarden, P.; Martin, K.R. Diabetic retinopathy: A complex pathophysiology requiring novel therapeutic strategies. Expert Opin. Biol. Ther. 2018, 18, 1257-1270. [CrossRef]

70. Mustafi, D.; Saraf, S.S.; Shang, Q.; Olmos de Koo, L.C. New developments in angiography for the diagnosis and management of diabetic retinopathy. Diabetes Res. Clin. Pract. 2020, 167, 108361. [CrossRef]

71. Schmidt-Erfurth, U.; Garcia-Arumi, J.; Bandello, F.; Berg, K.; Chakravarthy, U.; Gerendas, B.S.; Jonas, J.; Larsen, M.; Tadayoni, R.; Loewenstein, A. Guidelines for the Management of Diabetic Macular Edema by the European Society of Retina Specialists (EURETINA). Ophthalmologica 2017, 237, 185-222. [CrossRef]

72. Ellis, D.; Burgess, P.I.; Kayange, P. Management of Diabetic Retinopathy. Malawi Med. J. 2013, 25, 116-120.

73. Zarbin, M.A.; Smiddy, W.E. Diabetic Retinopathy Management. Surg. Retin. 2012, 2, 1-34. [CrossRef]

74. El Rami, H.; Barham, R.; Sun, J.K.; Silva, P.S. Evidence-Based Treatment of Diabetic Retinopathy. Semin. Ophthalmol. 2016, 32, 67-74. [CrossRef] [PubMed]

75. Honasoge, A.; Nudleman, E.; Smith, M.; Rajagopal, R. Emerging Insights and Interventions for Diabetic Retinopathy. Curr Diabetes Rep. 2019, 19, 1-16. [CrossRef] [PubMed]

76. Mohamed, Q.; Gillies, M.C.; Wong, T.Y. Management of Diabetic Retinopathy. J. Am. Med. Assoc. 2007, 298, 902. [CrossRef]

77. Deissler, H.L.; Lang, G.E. The Protein Kinase C Inhibitor: Ruboxistaurin. Dev. Ophthalmol. 2016, 55, 295-301. [CrossRef]

78. Wong, T.Y.; Sun, J.; Kawasaki, R.; Ruamviboonsuk, P.; Gupta, N.; Lansingh, V.; Maia, M.; Mathenge, W.; Moreker, S.; Muqit, M.M.K.; et al. Guidelines on Diabetic Eye Care The International Council of Ophthalmology Recommendations for Screening, Follow-up, Referral, and Treatment Based on Resource Settings. Ophthalmology 2018, 125, 1608-1622. [CrossRef]

79. Lang, G.E. Pharmacological Treatment of Diabetic Retinopathy. Ophthalmologica 2007, 221, 112-117. [CrossRef]

80. Dulull, N.; Kwa, F.; Osman, N.; Rai, U.; Shaikh, B.; Thrimawithana, T.R. Recent advances in the management of diabetic retinopathy. Drug Discov. Today 2019, 24, 1499-1509. [CrossRef]

81. Waisbourd, M.; Goldstein, M.; Loewenstein, A. Treatment of diabetic retinopathy with anti-VEGF drugs. Acta Ophthalmol. 2010, 89, 203-207. [CrossRef]

82. Neubauer, A.S.; Ulbig, M.W. Laser Treatment in Diabetic Retinopathy. Ophthalmologica 2007, 221, 95-102. [CrossRef] [PubMed]

83. Ellis, M.P.; Lent-Schochet, D.; Lo, T.; Yiu, G. Emerging Concepts in the Treatment of Diabetic Retinopathy. Curr. Diabetes Rep. 2019, 19, 137. [CrossRef] [PubMed]

84. DeLacruz, J.P.G.; Correa, J.A.G. Pharmacological approach to diabetic retinopathy. Diabetes Metab. Res. Rev. 2004, 20,91 r113.

85. Leal, E.; Santiago, A.; Ambrosio, A. Old and New Drug Targets in Diabetic Retinopathy: From Biochemical Changes to Inflammation and Neurodegeneration. Curr. Drug Target-CNS Neurol. Disord. 2005, 4, 421-434. [CrossRef] [PubMed]

86. Barot, M.; Gokulgandhi, M.R.; Patel, S.; Mitra, A.K. Microvascular complications and diabetic retinopathy: Recent advances and future implications. Future Med. Chem. 2013, 5, 301-314. [CrossRef] 